\title{
Variants of Shiga-like toxin II constitute a major toxin component in Escherichia coli 0157 strains from patients with haemolytic uraemic syndrome
}

\author{
H. RÜSSMANN, H. SCHMIDT, J. HEESEMANN, A. CAPRIOLI* and H. KARCH†
}

Institut für Hygiene und Mikrobiologie der Universität Würzburg, Josef-Schneider-Str. 2, Bau 17, 97080 Würzburg, Germany and * Laboratorio di U/trastrutture, Istituto Superiore di sanità, Viale Regina Elena, 229, 00161 Rome, Italy

\begin{abstract}
Summary. The prevalence and genotype of Shiga-like toxins (SLTs) in Escherichia coli O157 strains from patients in Germany with haemolytic uraemic syndrome (HUS) were investigated. This was done by PCR amplification of the B-subunit genes with two primer pairs-one complementary to sIt-IB, and the other homologous to both slt-IIB and slt-IIvB sequences. To distinguish between slt-II and slt-IIv, the amplified DNA was digested with restriction endonucleases HaeIII and FokI. Of the 38 strains examined, 17 harboured sequences for $s l t-I I v$; four contained only slt-IIV, three carried both slt-IIv and slt-I, and 10 strains had slt-IIv and slt-II. A further three genotypes (slt-I, slt-II, slt-I/slt-II) were found in the remaining 21 strains resulting in a total of six slt genotypes. To determine whether the slt genes were expressed, and whether genotypes correlated with phenotypes, all strains were subjected to cytotoxicity assays and colony ELISA. All 38 strains displayed cytotoxic activity to Vero cells in similar quantities. The SLT-I-specific monoclonal antibody (MAb)13C4 reacted with all 10 strains in which $s l t-I$ sequences were identified. Colony blot ELISA with the SLT-II specific MAb11E10 detected 27 of 28 strains with slt-II sequences, but did not react with any of the seven strains that carried slt-IIv, or slt-I and slt-IIv. The high SLT variability shown here has diagnostic implications and may well have consequences for the host response in infections associated with these pathogens.
\end{abstract}

\section{Introduction}

Escherichia coli $\mathrm{O} 157$ strains are the major cause of haemorrhagic colitis and haemolytic uraemic syndrome (HUS). The Shiga-like toxins (SLTs), also called verocytotoxins, which they produce, are divided into two major groups, Shiga-like toxin I (SLT-I) and Shiga-like toxin II (SLT-II) on the basis of immunological and molecular characteristics. SLT-I toxins appear to be homogeneous and are neutralised by antibody against the Shiga toxin of Shigella dysenteriae type I. ${ }^{1-4}$ SLT-II toxins are heterogeneous and are not neutralised by polyclonal Shiga antitoxin or SLT-I antitoxin. ${ }^{5,6}$ Only $58 \%$ of the overall nucleotide sequence homology is shared by slt-I and slt-II. ${ }^{7}$ The SLT-II variants, SLT-IIc and SLT-IIvhc, have been identified recently in E. coli $\mathrm{O} 157: \mathrm{H}^{-}$strain E32511 and $E$. coli $\mathrm{O} 157: \mathrm{H} 7$ strain 7279 , respectively. ${ }^{8,9}$ When compared to slt-II, slt-IIc and slt-IIvhc share c. $99 \%$ and $95 \%$ homology in their respective A- and B-subunit genes. Furthermore, slt-IIc and slt-IIvhc exhibit almost identical nucleotide sequences. ${ }^{8}$ The predicted amino-acid sequences of their B subunits are identical. Additional SLT-II variants have been described in non-O157 E. coli strains $^{5,6,10-12}$ and in Citrobacter freundii. ${ }^{13}$ Although SLT-II variants are highly related to SLT-II at the nucleotide and protein level, they are not completely neutralised by antibodies against SLT-II. Furthermore, it has been demonstrated that SLT-IIv differs from SLT-II in its carbohydrate-binding specificities for target cell receptors. ${ }^{14}$

Different findings have been reported for the frequency of SLT-II-variants in E. coli 0157 strains. None of the 24 E. coli $\mathrm{O} 157$ strains studied by Hii et $a l .^{15}$ carried slt-IIv sequences, whereas all eight strains analysed by Tyler et al. ${ }^{16}$ had them. However, the association between disease and individual toxins was not reported. Therefore, we examined the frequency of SLT-IIv among E. coli $\mathrm{O} 157$ strains from patients with HUS and performed a complete slt genotyping analysis to determine whether there was an association between individual toxins and disease.

\section{Materials and methods}

\section{Bacterial strains}

The 38 E. coli $\mathrm{O} 157$ strains used in this study are 
listed in the table. They were isolated from the stools of 38 children with HUS treated in different paediatric centres in different geographical locations throughout Germany. As far as is known, there was no contact between any of the patients. Of the $38 \mathrm{E}$. coli $\mathrm{O} 157$ strains, 15 were identified by colony hybridisation with probes 772 and 849 as described previously, ${ }^{17}$ and 23 strains were identified by colony hybridisation with digoxigenin-labelled PCR products from the slt-IB- or the $s i t-I I B$ genes prepared as described previously. ${ }^{13}$ All strains gave a negative sorbitol reaction in liquid medium and on sorbitol MacConkey agar. Sorbitolfermenting E. coli $\mathrm{O} 157: \mathrm{H}^{-}$strains described previously ${ }^{18}$ were not examined because they all produced SLT-II. ${ }^{18,19}$ The control strains used in the slt genotyping studies were the $E$. coli lysogen C600(933W) that produces SLT-II, E. coli strain E32511 that produces SLT-IIv, E. coli strain $1249 / 87$ and E. coli strain 3978/91 that both produce SLT-II and -IIv, and E. coli strain C600 (H19J) that produces SLT-I.

\section{$P C R$ and restriction analysis}

The oligonucleotides used as primers were purchased from Roth, Karlsruhe, Germany. The sequences of the primers used to amplify the slt-IIB and slt-IIvB genes were GK5 (5'-ATG AAG AAG ATG TTT ATG GCG-3') and GK6 (5'-TCA GTC ATT ATT AAA CTG CAC-3'). The primers KS7 and $\mathrm{KS} 8^{13}$ were used to amplify the $s l t-I B$ gene. Bacterial DNA was prepared by incubating $10 \mu \mathrm{l}$ of bacterial suspension $\left(10^{4}\right.$ bacteria) for $10 \mathrm{~min}$ at $95^{\circ} \mathrm{C}$. Amplifications were performed in a total volume of $50 \mu \mathrm{l}$ which contained $200 \mu \mathrm{M}$ deoxynucleoside triphosphates (dATP, dCTP, dGTP and dTTP), $30 \mathrm{pmol}$ of each primer, $5 \mu \mathrm{l}$ of 10 -fold concentrated polymerase synthesis buffer and $2.5 \mathrm{U}$ of Taq DNA polymerase (Amersham Laboratories, Buckinghamshire). The samples were overlaid with $50 \mu$ l of mineral oil to prevent evaporation and subjected to 30 cycles of amplification. The samples were incubated at $94^{\circ} \mathrm{C}$ for $30 \mathrm{~s}$ to denature the DNA, for $1 \mathrm{~min}$ at $52^{\circ} \mathrm{C}$ to anneal the primers and at $72^{\circ} \mathrm{C}$ for $1 \mathrm{~min}$ to extend the annealed primers. Thermal cycling was performed in a thermostatically controlled waterbath. After the last cycle, the amplification products were subjected to submarine gel electrophoresis in agarose $2 \%$ gels and visualised by staining with ethidium bromide.

To distinguish between $s l t-I I B$ - and $s l t-I I v B$-related sequences, restriction analysis of the PCR amplification products obtained with primers GK5 and GK6 was performed according to the method of Tyler et $a l .,{ }^{16}$ with minor modifications. Briefly, $10-\mu \mathrm{l}$ amounts of the amplified products were digested with restriction endonucleases HaeIII and FokI (Boehringer Mannheim $\mathrm{GmbH}$, Mannheim, Germany) as recommended by the suppliers and the DNA fragments were separated and visualised as described above. It was expected from the published sequences of $s l t-I I B^{9}$ and slt-IIv $B^{20}$ that the digestion of the slt-IIB amplicon with FokI would yield two fragments of $116 \mathrm{bp}$ and $154 \mathrm{bp}$, whereas the slt-IIvB PCR product would remain undigested. Digestion of the slt-IIvB amplicon with HaeIII would yield a 128-bp and a 142-bp fragment but the slt-IIB PCR product would remain undigested. ${ }^{16}$

\section{Southern blot hybridisation}

For Southern blot analysis, total bacterial DNA was prepared as described previously, ${ }^{13}$ digested with $E c o$ RI and electrophoresed through an agarose $0.7 \%$ gel. The conditions for DNA transfer on to nylon membranes, capillary blotting and stringent hybridisation were as described previously. ${ }^{13}$

A 270-bp fragment of the slt-IIB gene resulting from amplification with the primers GK5 and GK6 was labelled with digoxigenin and used as a hybridisation probe. Probe labelling was performed by the PCR programme for the slt-IIB gene, but instead of dTTP only, a mixture of $130 \mu \mathrm{M}$ dTTP and $70 \mu \mathrm{M}$ digoxigenin-11-dUTP was added. Hybridisation and detection of bound probes were performed with the digoxigenin labelling and detection kit (Boehringer Mannheim) according to the manufacturer's instructions.

\section{Cytotoxicity assay}

Culture filtrates of all strains were tested for cytotoxic activity on Vero cells as described previously. ${ }^{13}$ The $50 \%$ cytotoxic dose was estimated by microscopic examination of the Vero cells after $48 \mathrm{~h}$ and was confirmed by staining residual Vero cells with crystal violet. ${ }^{13}$

\section{Colony blot ELISA for detection of SLTS}

The colony blot ELISA was performed in the presence of trimethoprim-sulphamethoxazole as described previously. ${ }^{21}$ The SLT-II-specific MAb $11 \mathrm{E} 10^{22}$ and the SLT-I-specific MAb $13 \mathrm{C} 4{ }^{20}$ were used in the assay.

\section{Results}

\section{PCR strategy and restriction fragment length polymorphism for genotyping SLTS}

In an initial attempt to subdivide the strains with respect to their toxin genes, each isolate was subjected to PCR analysis with primers specific for slt-IB. As shown in the table, 10 of the $38 \mathrm{E}$. coli O157 strains showed a positive PCR result. Primers GK5 and GK6 that identify both slt-II and slt-IIvB subunit genes were then evaluated with four control strains that carried either slt-II, slt-IIv, or both. Their PCR products were analysed on agarose gels, yielding DNA bands of $c .270 \mathrm{bp}$ (fig. 1A, lanes 1-4). These PCR 
Table. Differentiation of Shiga-like toxins from E. coli 0157 strains isolated from patients with HUS

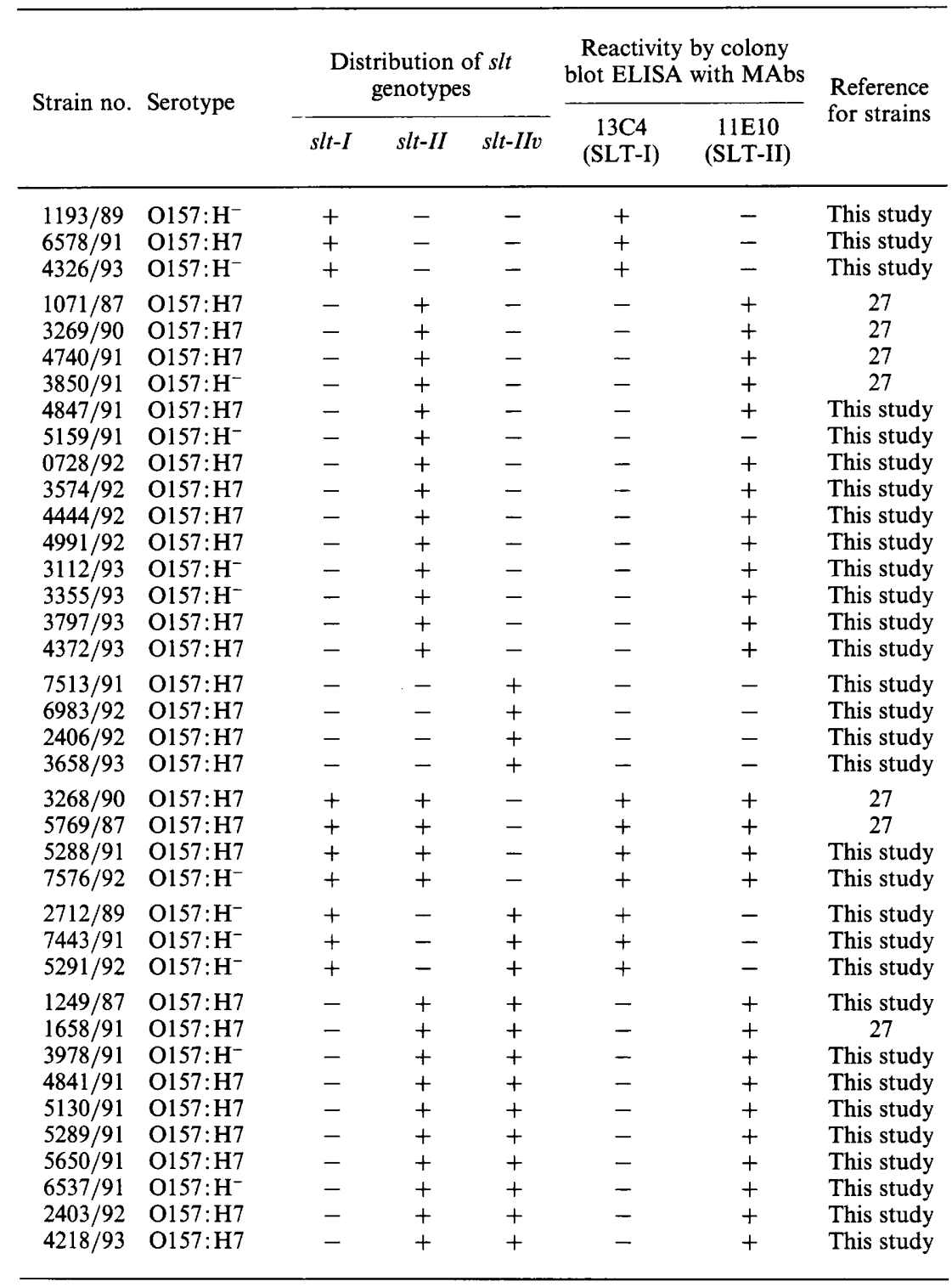

products were subjected to restriction endonuclease analyses. Figs. $1 \mathrm{~B}$ and $\mathrm{C}$ show the fragments resulting from digestion with FokI and HaeIII, respectively. It can be seen from fig. 1B, lane 1, that the PCR product of the SLT-II-producing strain was digested by FokI into a smaller fragment, which is believed to consist of two fragments that were not separable on this gel. The PCR product of the SLT-IIv-producing strain remained undigested (fig. 1B, lane 2) and both a digested and an undigested fragment were seen from strains producing both SLT-II and SLT-IIv (fig. 1B, lanes 3 and 4). Fig. 1C demonstrates the results of restriction analyses with HaeIII. The PCR product from the SLT-II-producing strain remained undigested (lane 1), whereas that from the SLT-IIvproducing strain was digested (lane 2). As expected, the PCR products of the two strains producing both SLT-II and SLT-IIv consisted of both a digested and an undigested fragment band (lanes 3 and 4).
Southern hybridisation of genomic DNA from the four control strains producing SLT-II, SLT-IIv and both these toxins is shown in fig. 2B, lanes 3-6. DNA from the non-toxigenic $E$. coli strain $\mathrm{C} 600$ and the slt$I$-expressing $E$. coli strain $\mathrm{C} 600(\mathrm{H} 19 \mathrm{~J})$ were included as negative controls (lanes 1 and 2 respectively). For the strains producing only SLT-II or SLT-IIv, a single $E c o$ RI fragment of either $4.6 \mathrm{~kb}$ (fig. 2B, lane 3 ) or $4.9 \mathrm{~kb}$ (fig. 2B, lane 4) hybridised with the slt-IIB probe. For the two strains possessing sequences for both slt-II and slt-IIv, two EcoRI fragments hybridised with the probe (fig. 2B, lanes 5 and 6).

\section{Prevalence of SLT-IIv, SLT-I and SLT-II in E. coli 0157 strains}

Restriction endonuclease analysis with $\mathrm{HaeIII}$ and FokI was performed on PCR products from all the strains after amplification with the primers GK5 and 
A
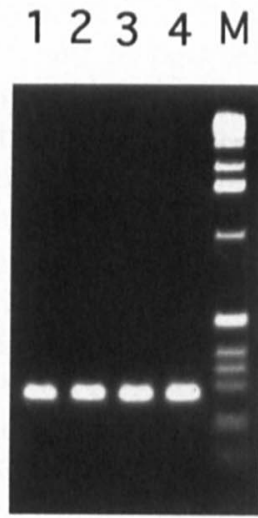

B
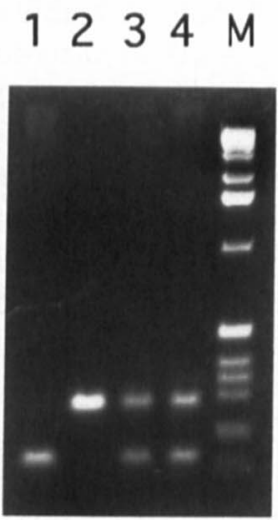

C

\section{$1234 M$}

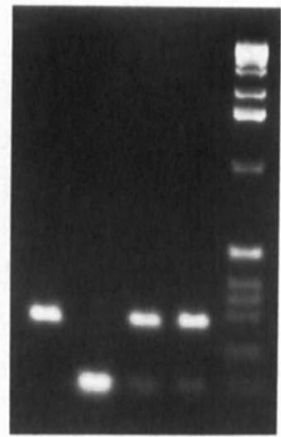

$k b$

$-1 \cdot 0$

$-0.5$

$-0.3$

$-0 \cdot 15$

Fig. 1. A, PCR amplification products with primers GK5 and GK6 to detect slt-IIB and slt-IIvB sequences. Lane 1: E. coli C600 ( $933 \mathrm{~W})$ (sltII); 2: E. coli E32511 (slt-IIv); 3: E. coli 1249/87 (slt-II and slt-IIv); 4: E. coli 3978/91 (slt-II and slt-IIv). Restriction fragment length polymorphism analysis of the PCR products with: B, FokI; C, HaeIII. M, DNA mol.-wt marker V (Boehringer Mannheim) is shown on the right.

A

B

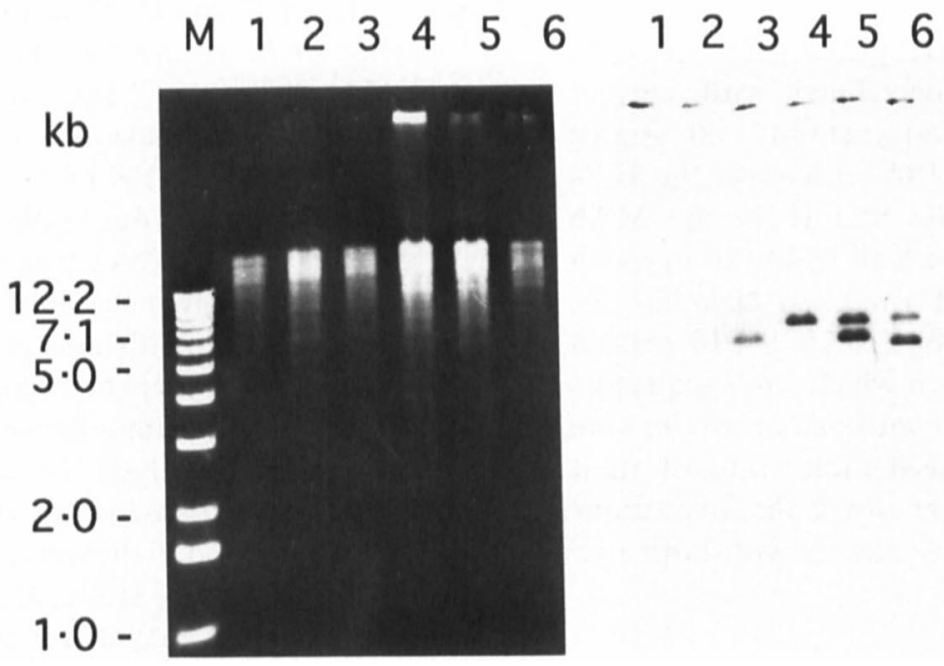

Fig. 2. A, Agarose gel electrophoresis of $E c o$ RI digested DNA fragments; B, Southern blot hybridisation with the slt-IIB probe. The isolates from which DNA samples were obtained were: lane 1, E. coli $\mathrm{C} 600 ; \mathbf{2}$, E. coli $\mathrm{C} 600(\mathrm{H} 19 \mathrm{~J}) ; \mathbf{3}$, E. coli $\mathrm{C} 600(933 \mathrm{~W}) ; \mathbf{4}$, E. coli E32511; 5, E. coli $1249 / 87 ; 6$, E. coli 3978/91. M, DNA mol.-wt marker V (Boehringer Mannheim) is shown on the left.

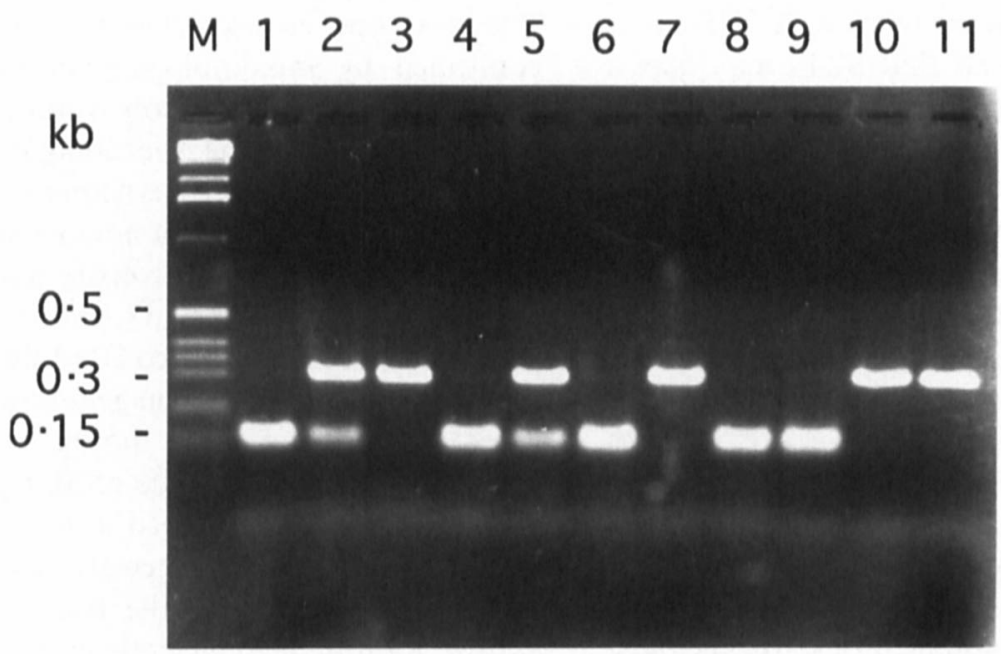

Fig. 3. Determination of $E$. coli $\mathrm{O} 157$ slt-II genotypes by restriction endonuclease analysis with HaeIII. Amplification products obtained by PCR with primers GK5 and GK6 were digested with HaeIII. The following E. coli strains were amplified: lane 1, 7513/91; 2, 1249/87; 3, $3269 / 90 ; 4,6983 / 91 ; 5,1658 / 91 ; 6,2406 / 92 ; 7,3850 / 91 ; 8,3658 / 93 ; 9,2712 / 89 ; 10,4847 / 91 ; 11,5159 / 91$. M, DNA mol.-wt marker V (Boehringer Mannheim) is shown on the left. 
GK6. Analysis of the PCR products from 11 strains after digestion with $\mathrm{Hae} I \mathrm{II}$ is shown in fig. 3. From this analysis: the PCR products shown in lanes $1,4,6,8$ and 9 are derived from slt-IIv; those in lanes 3, 7, 10 and 11 from slt-II: and the digested amplified DNA in lanes 2 and 5 contained both slt-II and slt-IIv. The results from the restriction endonuclease analyses of the PCR products obtained from the individual $E$. coli O157 strains are presented in the table. No discrepancy was seen between the results of the restriction endonuclease analyses performed with HaeIII and FokI.

\section{Cytotoxic activity and SLT-II neutralisation}

In liquid cultures, all the E. coli $\mathrm{O} 157$ isolates produced cytotoxin. In the four strains that produced only SLT-IIv, the cytotoxic activity was similar to that of the SLT-II producers, i.e., $10^{5}-10^{7} 50 \%$ cytotoxic doses/ml of culture supernate.

\section{Colony blot ELISA}

To determine whether the slt genes were expressed, and whether genotyping correlated with current immunological SLT-detection methods, all strains were subjected to colony ELISA with either the SLT I-specific MAb $13 \mathrm{C} 4$ or the SLT-II-specific MAb $11 \mathrm{E} 10 . \mathrm{MAb} 13 \mathrm{C} 4$ reacted with all 10 strains in which slt-I sequences were found (slt-I, slt-I/slt-IIv, slt$I /$ slt-II) as shown in the table. MAb 11 E10 reacted with 27 of $28 E$. coli strains in which slt-II sequences (either as the sole genotype or with $s l t-I$ or $s l t-I I v$ ) were identified. It was of considerable interest that MAb 11E10 did not recognise any of the four strains with slt-IIv alone or the three strains with both slt-I and slt-IIv sequences.

\section{Discussion}

The frequency of infections by SLT-producing $E$. coli $\mathrm{O} 157$ continues to increase worldwide. ${ }^{23}$ There is evidence from animal models that SLTs may play a crucial role in the pathogenesis of both intestinal and extra-intestinal manifestations of E. coli $\mathrm{O} 157$ infection. ${ }^{24-26}$ In addition to SLT-I and SLT-II, there is a growing interest in variants of SLT-II that previously were undetectable because of their high nucleotide homology to SLT-II. By means of PCR amplification and subsequent restriction endonuclease analysis, we have demonstrated the impact of SLT-IIv in clinical isolates of $E$. coli $\mathrm{O} 157$. Of the $38 E$. coli $\mathrm{O} 157$ strains tested, 17 contained slt-IIv sequences, either alone or in combination with slt-I or slt-II. In total, six combinations of slt genotypes were detected: $s l t-I$, slt$I I$, slt-IIV, slt-I/slt-II, slt-I/slt-IIv and slt-II/slt-IIv. These findings may have implications for the host response in $E$. coli $\mathrm{O} 157$ infections.

The considerable toxin diversity is an interesting phenomenon because multilocus enzyme electro- phoresis and DNA fingerprinting have provided epidemiological evidence that $E$. coli $\mathrm{O} 157$ strains are highly related. ${ }^{27,}{ }^{28}$ The relatively low degree of genetic variation observed in the $\mathrm{O} 157$ population suggests that the pathogen probably arose from a single clone. ${ }^{28}$ At first sight, this genomic homogeneity appears to be in contrast to the SLT heterogeneity. The simplest explanation for SLT diversity would be that an ancestral isolate contained slt-I, slt-II and slt-IIv. Loss of any one or two slts would result in the six genotypes found. Loss of slt genes has been reported in both $E$. coli $\mathrm{O} 157$ and non-O157 toxin producers. ${ }^{9,29}$ Thomas et al $^{30}$ reported recently on E. coli $\mathrm{O} 157$ strains reacting with oligonucleotides specific for the three toxins. However, of the E. coli $\mathrm{O} 157$ strains investigated here, no isolate was found that harboured all three toxins.

Molecular methods involving PCR, oligonucleotide DNA probes and Southern hybridisation have been used to subdivide the SLT-II family. Variable results have been reported on the prevalence of SLT-IIv. None of the $24 E$. coli 0157 strains studied by Hii et $a l .^{15}$ carried $s l t-I I v$ sequences, whereas all eight strains examined by Tyler et al. ${ }^{16}$ possessed $s l t-I I v$. In strains from Britain, an oligonucleotide homologous to slt-IIv sequences reacted with 109 of 176 isolates, ${ }^{30}$ an SLTIIv frequency similar to our findings. The variation in prevalence may depend on the methodology used for SLT-IIv identification or the source of the strains. We adopted the strategy of Tyler et al ${ }^{16}$ to identify SLTIIv, i.e., the use of primers homologous to SLT-II and SLT-IIv and distinguishing between the slt genes by restriction enzyme analysis. Initial investigations in our laboratory compared the restriction enzymes HaeIII, RsaI and NciI in differentiating between SLTII and SLT-IIv. ${ }^{18}$ In our study, HaeIII was confirmed as the most suitable enzyme for the digestion of slt$I I v B$. To digest $s l t-I I B$ selectively, we introduced FokI. This was found to be superior to RsaI, for minimal amounts of the amplified DNA remained undigested and the genotype of SLT could be predicted correctly. The genotype as predicted by FokI digestion was confirmed by immunological detection of SLT-II. Further detailed study on variants of SLT-II is required to determine the complete nucleotide sequence, in order to assess whether or not the SLT-IIv of E. coli $\mathrm{O} 157$ strains is a homogeneous toxin.

Our findings on SLT diversity may be of epidemiological value. E. coli $\mathrm{O} 157$ strains which have been shown to have highly related DNA fingerprints ${ }^{27}$ might be subdivided by their toxin genotype. However, as slt genes may be easily lost during storage or in vivo, further studies on the value of SLT genotyping as an epidemological marker need to be done.

SLT genotype heterogeneity may also have an important influence on the host response, because anti-SLT antibodies efficiently neutralise the cytotoxic effect by interference with receptor binding. ${ }^{25}$ Therefore, antitoxic immunity appears to be important in the immune response against $E$. coli $\mathrm{O} 157$-associated 
disease. Because little is known at present about the prevalence of SLT-specific antibodies in man, SLT- diversity might contribute to the high virulence of $E$. coli $\mathrm{O} 157$ strains.

\section{References}

1. Calderwood SB, Auclair F, Donohue-Rolfe A, Keusch GT, Mekalanos JJ. Nucleotide sequence of the Shiga-like toxin genes of Escherichia coli. Proc Natl Acad Sci USA 1987; 84: 4364-4368.

2. Jackson MP, Newland JW, Holmes RK, O'Brien AD. Nucleotide sequence analysis of the structural genes for Shiga-like toxin I encoded by bacteriophage 933J from Escherichia coli. Microb Pathog 1987; 2: 147-153.

3. Takao T, Tanabe T, Hong YM et al. Identity of molecular structure of Shiga-like toxin I (VT1) from Escherichia coli O157:H7 with that of Shiga toxin. Microb Pathog 1988; 5: 57-69.

4. Karmali MA. Infection by verocytotoxin-producing Escherichia coli. Clin Microbiol Rev 1989; 2: 15 38 .

5. Gannon VP, Teerling C, Masri SA, Gyles CL. Molecular cloning and nucleotide sequence of another variant of the Escherichia coli Shiga-like toxin II family. J Gen Microbiol 1990; 136: 1125-1135.

6. Paton AW, Paton JC, Heuzenroeder MW, Goldwater PN, Manning PA. Cloning and nucleotide sequence of a variant Shiga-like toxin II gene from Escherichia coli $\mathrm{OX} 3: \mathrm{H} 21$ isolated from a case of sudden infant death syndrome. Microb Pathog 1992; 13: 225-236.

7. Newland JW, Strockbine NA, Neill RJ. Cloning of genes for production of Escherichia coli Shiga-like toxin type II. Infect Immun 1987; 55: 2675-2680.

8. Meyer T, Karch $\mathrm{H}$, Hacker J, Bocklage H, Heesemann J Cloning and sequencing of a Shiga-like toxin II-related gene from Escherichia coli O157: H7 strain 7279. Int J Med Microbiol Virol Parasitol Infect Dis 1992; 276: 176-188.

9. Schmitt CK, McKee ML, O'Brien AD. Two copies of Shiga-like toxin II-related genes common in enterohemorrhagic Escherichia coli strains are responsible for the antigenic heterogeneity of the $\mathrm{O} 157: \mathrm{H}^{-}$strain E32511. Infect Immun 1991; 59: 1065-1073.

10. Gyles CL, De Grandis SA, MacKenzie C, Brunton JL. Cloning and nucleotide sequence analysis of the genes determining verocytotoxin production in a porcine edema disease isolate of Escherichia coli. Microb Pathog 1988; 5: 419-426.

11. Ito H, Terai A, Kurazono H, Takeda Y, Nishibuchi M. Cloning and nucleotide sequencing of Vero toxin 2 variant genes from Escherichia coli $\mathrm{O} 91: \mathrm{H} 21$ isolated from a patient with the hemolytic uremic syndrome. Microb Pathog 1990; 8: 47-60 (erratum, p. 449).

12. Weinstein DL, Jackson MP, Samuel JE, Holmes RK, O'Brien $\mathrm{AD}$. Cloning and sequencing of a Shiga-like toxin type II variant from Escherichia coli strain responsible for edema disease of swine. $J$ Bacteriol $1988 ; 170: 4223-4230$.

13. Schmidt H, Montag M, Bockemühl J, Heesemann J, Karch $\mathbf{H}$. Shiga-like toxin II-related cytotoxins in Citrobacter freundii strains from humans and beef samples. Infect Immun 1993; 61: $534-543$.

14. Samuel JE, Perera LP, Ward S, O'Brien AD, Ginsburg V, Krivan HC. Comparison of the glycolipid receptor specificities of Shiga-like toxin type II and Shiga-like toxin type II variants. Infect Immun 1990; 58: 611-618.

15. Hii JH, Gyles C, Morooka T et al. Development of verotoxin 2

and verotoxin 2 variant (VT2v)-specific oligonucleotide probes on the basis of the nucleotide sequence of the cistron of VT2v from Escherichia coli $\mathrm{E} 32511$ and B2F1. $J$ Clin Microbiol 1991; 29: 2704-2709.

16. Tyler SD, Johnson WM, Lior H, Wang G, Rozee KR. Identification of verotoxin type 2 variant $B$ subunit genes in Escherichia coli by the polymerase chain reaction and restriction fragment length polymorphism analysis. $J$ Clin Microbiol 1991; 29: 1339-1343.

17. Karch H, Meyer T. Evaluation of oligonucleotide probes for identification of shiga-like-toxin-producing Escherichia coli. J Clin Microbiol 1989; 27 : 1180-1186.

18. Gunzer F, Böhm H, Rüssmann H, Bitzan M, Aleksic S, Karch H. Molecular detection of sorbitol-fermenting Escherichia coli $\mathrm{O} 157$ in patients with hemolytic-uremic syndrome. $J$ Clin Microbiol 1992; 30: 1807-1810.

19. Karch H, Böhm H, Schmidt H, Gunzer F, Aleksic S, Heesemann J. Clonal structure and pathogenicity of Shigalike toxin-producing, sorbitol-fermenting Escherichia coli O157: $\mathrm{H}^{-}$. J Clin Microbiol 1993; 31: 1200-1205.

20. Strockbine NA, Marques LRM, Holmes RK, O'Brien AD. Characterization of monoclonal antibodies against Shigalike toxin from Escherichia coli. Infect Immun 1985; 50: 695-700.

21. Karch H, Strockbine NA, O'Brien AD. Growth of Escherichia coli in the presence of trimethoprim-sulfamethoxazole facilitates detection of Shiga-like toxin producing strains by colony blot. FEMS Microbiol Lett 1986; 35: 141-145.

22. Perera LP, Marques LR, O'Brien AD. Isolation and characterization of monoclonal antibodies to Shiga-like toxin II of enterohemorrhagic Escherichia coli and use of the monoclonal antibodies in a colony enzyme-linked immunosorbent assay. $J$ Clin Microbiol 1988; 26: 2127-2131.

23. Knight P. Hemorrhagic $E$. coli: the danger increases. $A S M$ News 1993; 59: 247-250.

24. MacLeod DL, Gyles CL, Wilcock BP. Reproduction of edema disease of swine with purified Shiga-like toxin-II variant. Vet Pathol 1991; 28: 66-73.

25. Richardson SE, Rotman TA, Jay V et al. Experimental verocytotoxemia in rabbits. Infect Immun 1992; 60: 41544167.

26. O'Brien AD, Tesh VL, Donohue-Rolfe A et al. Shiga toxin: biochemistry, genetics, mode of action, and role in pathogenesis. Curr Top Microbiol Immunol 1992 ; 180 : 65-94.

27. Böhm H, Karch $\mathrm{H}$. DNA fingerprinting of Escherichia coli O157:H7 strains by pulsed-field gel electrophoresis. $J$ Clin Microbiol 1992; 30: 2169-2172.

28. Whittam TS, Wachsmuth IK, Wilson RA. Genetic evidence of clonal descent of Escherichia coli O157:H7 associated with hemorrhagic colitis and hemolytic uremic syndrome. $J$ Infect Dis 1988; 157: 1124-1133.

29. Karch H, Meyer T, Rüssmann H, Heesemann J. Frequent loss of Shiga-like toxin genes in clinical isolates of Escherichia coli upon subcultivation. Infect Immun 1992; 60: 3464-3467.

30. Thomas A, Smith HR, Rowe B. Use of digoxigenin-labelled oligonucleotide DNA probes for VT2 and VT2 human variant genes to differentiate vero cytotoxin-producing Escherichia coli strains of serogroup O157. J Clin Microbiol $1993 ; 31: 1700-1703$. 